\title{
Relationship of chronic endurance exercise to the somatotropic and sex hormone status of older men
}

\author{
Carolyn S Cooper ${ }^{1,2}$, Dennis R Taaffe ${ }^{1,2}$, David Guido ${ }^{1}$, Elizabeth Packer ${ }^{1}$, Leah Holloway ${ }^{1}$ and Robert Marcus ${ }^{1,2}$ \\ ${ }^{1}$ Aging Study Unit, Geriatric Research, Education and Clinical Center, Veterans' Affairs Medical Center, Palo Alto, California 94304, USA and \\ ${ }^{2}$ Department of Medicine, Stanford University, Stanford, California 94305, USA \\ (Correspondence should be addressed to R Marcus, Geriatrics Research, Education and Clinical Center 182-B, Department of Veterans' Affairs Medical \\ Center, 3801 Miranda Avenue, Palo Alto, California 94304, USA)
}

\begin{abstract}
To investigate putative abrogating effects of habitual endurance exercise on age-related changes in endocrine function and body composition, we compared insulin-like growth factor-I (IGF-I), sex hormonal status and body composition in 15 Masters runners and 15 minimally exercising men (MEM) aged 60-70 years. A higher maximal oxygen uptake $\left(\mathrm{VO}_{2}\right.$ max.) in the runners $(41.4 \pm 1.6$ compared with $27.3 \pm 1.4 \mathrm{ml} / \mathrm{kg} / \mathrm{min}, P=0.0001$; mean \pm s.E.м.) reflected our group allocations. Analysis of body composition and bone mineral density (BMD) by dual energy X-ray absorptiometry showed no group differences in lean tissue mass or in regional or whole body BMD, but MEM were heavier, reflecting greater adiposity. Of nine muscle groups tested, only quadriceps strength differed significantly, being greater in runners $(60.3 \pm 2.8$ compared with $51.1 \pm 2.3 \mathrm{~kg}, P=0.02)$. Total IGF-I $(129 \pm 10$ compared with $124 \pm 11 \mathrm{ng} / \mathrm{ml}, P=0.72)$ and IGF-binding protein-3 $(2854 \pm 94$ compared with $2623 \pm 128 \mathrm{ng} / \mathrm{ml}, P=0.16$ ), were similarly depressed compared with young adult norms in both groups. There was no relationship between total or bioavailable IGF-I and any body composition, BMD or muscle strength variable. In the runners, concentrations of total testosterone $(19.1 \pm 0.8$ compared with $15.0 \pm 0.9 \mathrm{nmol} / \mathrm{l}, P=0.002)$ and sex hormone binding globulin (SHBG) $(124.4 \pm 21.6$ compared with $67.7 \pm 11.6 \mathrm{nmol} / \mathrm{l}, P=0.03)$ were significantly greater, but the free androgen index was significantly lower $(20.7 \pm 2.7$ compared with $31.4 \pm 4.1, P=0.04)$. Directly measured free testosterone, however, was similar between the runners and MEM $(47.9 \pm 1.8$ compared with $47.1 \pm 2.0 \mathrm{nmol} / \mathrm{l}, P=0.80$ ). Therefore the group differences in total testosterone and free androgen index were due to their different SHBG concentrations. Although estrone concentration was higher in MEM $(85.1 \pm 5.2$ compared with $108 \pm 6.7 \mathrm{pmol} / \mathrm{l}, P=0.03)$, estradiol concentration was similar between groups $(73.0 \pm 6.3$ compared with $81.8 \pm 8.0 \mathrm{pmol} / \mathrm{l}, P=0.18)$, indicating that estrogens were not responsible for the increased SHBG in runners. These results indicate that even high levels of regular endurance exercise do not prevent the decline in the somatotropic axis that occurs with aging. Furthermore, the somatic effects of exercise in older men (reduced adiposity and increased regional muscle strength) occurred independently of somatotropic or androgen status. Although habitual exercise does not influence free testosterone concentrations in older men, it appears to enhance the age-associated increase in SHBG synthesis.
\end{abstract}

European Journal of Endocrinology 138 517-523

\section{Introduction}

From about the fourth decade, human aging is associated with a decline in secretion of growth hormone $(\mathrm{GH})(1)$ and insulin-like growth factor (IGF)-I (2), a process that has been termed the 'somatopause'. Although mechanisms responsible for this phenomenon are incompletely understood, impaired GH release in response to a variety of physiologic and pharmacologic stimuli has been repeatedly documented $(3,4)$. Adults with complete $\mathrm{GH}$ deficiency typically manifest a reduced lean body mass and muscle strength, an increased fat mass and a reduced exercise capacity $(5,6)$. These abnormalities can be at least partially corrected by GH replacement (5-8). The body composition changes of complete GH deficiency are characteristic somatic features of normal human aging, which has therefore evoked the hypothesis that relative GH deficiency in later life may contribute to such changes (9).

Although resistance (3) and endurance exercise (10) acutely enhance $\mathrm{GH}$ release in young adults, we have recently shown that an acute period of resistance exercise in healthy older men and women did not significantly increase circulating $\mathrm{GH}$ (3), and that a year-long program of resistance training failed to improve their markedly attenuated GH and IGF-I responses (11). A number of 
authors have suggested that aerobic exercise might restore or maintain the integrity of IGF-I status in later life $(12-14)$, but these conclusions were inferred from weak statistical correlation (12), predicted rather than directly measured maximal aerobic capacity $\left(\mathrm{VO}_{2}\right.$ max.) (14) and on the basis of small increases in IGF-I without comparison against a control group (13).

Normal aging in men is also associated with a decline in circulating total testosterone and an increase in sex hormone-binding globulin (SHBG) (15), causing a reduction in bioavailable or free testosterone concentration (16). Several authors have reported lower concentrations of both total testosterone $(17,18)$ and free testosterone $(19,20)$ in young endurance-trained men compared with age-matched 'sedentary' controls, whereas others have observed no effect of endurance exercise on total testosterone concentrations $(21,22)$. Even if habitual endurance activity were to improve IGF-I production, an exercise-dependent attenuation of gonadal function might negate any potential benefits of the former on body composition. To assess these issues in greater detail, we undertook a cross-sectional evaluation of body composition and of components of the GH/IGF and gonadal axes in healthy minimally exercising men (MEM) and in extremely physically active older men.

\section{Participants and methods}

\section{Participants}

Healthy men aged 60-70 years, with a body mass index $\left(\mathrm{BMI} ; \mathrm{kg} / \mathrm{m}^{2}\right)$ of 30 or less, were recruited from the local community. Runners were recruited from several running and athletic organizations in our community that cater to older athletes. Enrollment criteria for this group included regular participation in endurance exercise for at least $2.5 \mathrm{~h}$ per week for the previous 10 years. Assignment to the minimally exercising group precluded regular participation in any exercise for more than $2.5 \mathrm{~h}$ per week for the previous 10 years. Volunteers were admitted to the Aging Study Unit, a clinical investigation ward, for a screening procedure that included a comprehensive health history, physical examination, urine analysis, fasting multiphasic laboratory profile, resting electrocardiography and a 4-day nutritional assessment questionnaire. No participant was taking any medications known to interfere with the hormonal variables being measured or with bone and mineral metabolism. The protocol was approved by the Human Subjects Committee of Stanford University, and all participants gave written consent to their inclusion in the study.

\section{Protocol}

Fifteen runners and 15 MEM met the entry criteria and were enrolled into the study. Having undertaken no physical exercise in the preceding $24 \mathrm{~h}$, the participants reported to the study unit. A 2-h urine collection was started at $0700 \mathrm{~h}$, and fasting blood samples were taken at $0800 \mathrm{~h}$. All participants subsequently underwent a treadmill exercise test, a muscle strength assessment, and an analysis of body composition and bone mineral density (BMD) by dual energy X-ray absorptiometry (DXA).

\section{Laboratory measurements}

Fasting blood samples were drawn from an antecubital vein. Specimens were centrifuged at 3000 r.p.m for $10 \mathrm{~min}$ and frozen at $-20^{\circ} \mathrm{C}$ for subsequent batch analysis in single assay runs. IGF-I and IGF-binding protein-3 (IGFBP-3) were measured by RIA as reported previously (23). Free testosterone was measured by RIA, using kits supplied by Diagnostic Systems Laboratories (DSL, Webster, TX, USA). Intra- and interassay coefficients of variation (CVs) for free testosterone were $8.6 \%$ and $4.8 \%$ respectively at a free testosterone concentration of $22.9 \mathrm{pg} / \mathrm{ml}$, and $7.6 \%$ and $7.7 \%$ at a free testosterone concentration of $2.2 \mathrm{pg} / \mathrm{ml}$. Total testosterone was measured by RIA (DSL). Intra- and interassay CVs were $6.8 \%$ and $7.7 \%$ respectively (at a total testosterone concentration of $5.4 \mathrm{ng} / \mathrm{ml}$ ). SHBG was measured by IRMA (DSL). Intra- and interassay CVs were $7.7 \%$ and $7.1 \%$ (at SHBG $24.1 \mathrm{nmol} / \mathrm{l}$ ) and $4.2 \%$ (at SHBG $103 \mathrm{nmol} / \mathrm{l}$ ). An index of 'free', biologically active testosterone, the free androgen index (FAI), was derived from the ratio total testosterone/ SHBG $\times 100$ (24). Urinary pyridinolines, and serum osteocalcin and collagen type I C-terminal propeptides (CICP), markers of bone turnover, were measured by RIA and IRMA as we have validated and reported previously (25). Estrone $\left(\mathrm{E}_{1}\right)$ and estradiol $\left(\mathrm{E}_{2}\right)$ were measured by RIA (DSL). Intra- and interassay CVs for $\mathrm{E}_{1}$ were $7.7 \%$ and $13.2 \%$ (at $\mathrm{E}_{1} 40.1 \mathrm{pg} / \mathrm{ml}$ ), and for $\mathrm{E}_{2}$ were $11.1 \%$ and $6.3 \%$ (at $\mathrm{E}_{2} 19.4 \mathrm{ng} / \mathrm{ml}$ ).

\section{Assessment of aerobic fitness}

All participants underwent a maximal oxygen test on a motorized treadmill (Quinton Q65; Quinton Corp., Seattle, WA, USA) with maximal oxygen uptake $\left(\mathrm{VO}_{2}\right.$ max.) determined by indirect calorimetry. The oxygen (Ametek S-3A/I; Ametek, Pittsburgh, PA, USA) and carbon dioxide (Ametek CD 3A; Ametek) analyzers were calibrated before each exercise test with a standardized gas mixture. The active group performed a procedure in which both the speed and degree of treadmill incline were progressively increased to $5.1 \mathrm{~km} / \mathrm{h}$ and up to $25^{\circ}$ (Balke protocol), and the minimally exercising group performed a procedure in which the treadmill speed remained at $3.3 \mathrm{~km} / \mathrm{h}$ and the angle of incline increased (modified Balke protocol) (26). During testing, heart rate, blood pressure and Borg Scale rating of perceived exertion (27) were periodically obtained. Testing was 
stopped when the participant was unable to continue. At that point, the respiratory quotient $(\mathrm{R})$ exceeded 1.00 in all cases and $\mathrm{VO}_{2}$ values had plateaued, indicating that $\mathrm{VO}_{2}$ max. had been reached.

Five men (two active and three MEM) did not complete $\mathrm{VO}_{2}$ max. testing. One was stopped because of ischemic changes on the electrocardiogram and the others because of ventricular ectopic beats occurring at a rate of more than $6 / \mathrm{min}(26)$. However, all other data collected from these men were included in the analysis.

\section{Strength measurements}

All participants underwent an individualized introductory session for familiarization with the strength testing equipment. Each returned at least 1 week later and underwent concentric muscle strength testing of all major muscle groups, using the one repetition maximum (1-RM) method (28). The 1-RM is the maximal weight an individual can lift once with acceptable form. Acceptable form means that the exercise is executed primarily by the recruitment of the target muscle groups, with only minimal involvement of other major muscle groups.

Biceps curl, triceps extension, leg press, bench press and military press were performed on a Multistation weight machine (Universal Gym Equipment, Cedar Rapids, IA, USA). Leg flexion and extension were performed on a Marcy Leg Trainer (Marcy Physical Fitness Products, Alhambra, CA, USA), and back extension on a Nautilus machine (Nautilus Sports/ Medical Industries, Independence, VA, USA). The coefficient of variation for repeated measures in our laboratory was $2.4-7.6 \%$ for all strength tests. Dominant and non-dominant hand grip strength were determined in triplicate by isometric dynamometry (Jamar, TEC, Clifton, NJ, USA).

\section{Body composition and bone mineral density analysis}

Whole body, femoral neck and lumbar spine $\left(\mathrm{L}_{2-4}\right)$ bone mineral density (BMD; $\mathrm{g} / \mathrm{cm}^{2}$ ), bone-free lean tissue mass (LTM; kg), total body fat mass (BFM; kg) and percent body fat were assessed by DXA (Hologic QDR 1000/W, Waltham, MA, USA; whole body software version 5.47, spine and hip software version 6.1). In our laboratory, the $\mathrm{CV}$ for replicate measurements of body composition and BMD variables by DXA is $1.5 \%$ or less for older men.

\section{Statistical analysis}

Data were analyzed with Statview II software package (Abacus Concepts, Berkeley, CA, USA). Analysis included descriptive statistics, unpaired two-tailed $t$-tests, linear regression and stepwise regression. Because of the relatively small sample size, group comparisons were also made using Mann-Whitney $U$ tests. In no case did the results of Mann-Whitney tests differ from those of $t$-tests; the reported $P$ values reflect the Mann-Whitney $U$ tests. Correlation coefficients were derived from the linear regression program. An $\alpha$ level of 0.05 was taken as the criterion for significance. All values are expressed as the mean \pm s.E.M. Fifteen participants per group provided adequate power to detect a difference in IGF-I concentration of $40 \mathrm{ng} / \mathrm{ml}(\beta=0.2, P<0.05)$, and the differences in SHBG were so great that statistical significance was achieved with this sample size.

\section{Results}

Characteristics of the study group are shown in Table 1. Runners were lighter and had less adiposity than the MEM. Both groups had similar LTM, but when this was adjusted for body surface area (LTM/height ${ }^{2}$ ) the MEM had a significantly greater value than the runners. Absolute (l/min) and relative $(\mathrm{ml} / \mathrm{kg} / \mathrm{min}) \mathrm{VO}_{2}$ max. were significantly greater in the runners, even when normalized to LTM. Macro- and micronutrient analysis of nutritional questionnaires were comparable between the groups (data not shown).

\section{Somatotropic and sex hormones}

Serum total IGF-I and IGFBP-3 concentrations were similar in the two groups (Table 2), as was the ratio of IGF-I:IGFBP-3, which has been considered by some authors to reflect bioavailable IGF-I (29). Total testosterone and SHBG concentrations were significantly greater in the runners, but the FAI was significantly lower. Free testosterone concentrations were similar between runners and MEM. $\mathrm{E}_{1}$, but not $\mathrm{E}_{2}$, concentrations were significantly lower in the runners than in the MEM.

\section{Bone density, body composition and muscle strength}

There was no inter-group difference for regional or whole body BMD, even when normalized to body weight (whole body, $P=0.15$; femoral neck, $P=0.08$; lumbar spine, $P=0.31$; Table 1 ). Although no significant difference existed for markers of bone turnover, a trend towards higher values was observed in the runners (Table 2). Concentric muscle strength was comparable for the two groups, except for leg extension, for which the runners were significantly stronger (Table 3).

\section{Relationships among study variables}

Circulating IGF-I did not correlate significantly with adiposity $(r=0.30, P=0.17)$, LTM $(r=0.23, P=0.22)$ or BMD at any site (whole body $r=0.02, P=0.94$; femoral neck $r=0.21, P=0.27$; lumbar spine $r=0.01$, 
Table 1 Characteristics of study participants. Values are means \pm S.E.M.

\begin{tabular}{lccc}
\hline & Runners $(n=15)$ & Minimal exercisers $(n=15)$ & $* \boldsymbol{P}$ value \\
\hline Age $(\mathrm{year})$ & $64.2 \pm 0.7$ & $64.7 \pm 0.9$ & 0.95 \\
Height $(\mathrm{cm})$ & $177.2 \pm 1.4$ & $175.4 \pm 1.4$ & 0.35 \\
Weight $(\mathrm{kg})$ & $73.8 \pm 1.8$ & $84.8 \pm 4.0$ & 0.04 \\
$\mathrm{BMI}\left(\mathrm{kg} / \mathrm{m}^{2}\right)$ & $23.5 \pm 0.5$ & $27.5 \pm 1.2$ & 0.002 \\
$\mathrm{VO}_{2}$ max. $(\mathrm{ml} / \mathrm{kg} / \mathrm{min}) \dagger$ & $41.4 \pm 1.6$ & $27.3 \pm 1.4$ & 0.0001 \\
$\mathrm{VO}_{2}$ max. $(\mathrm{min}) \dagger$ & $2.89 \pm 0.09$ & $2.23 \pm 0.13$ & 0.0003 \\
$\mathrm{VO}_{2}$ max. $(\mathrm{ml} / \mathrm{kgLTM} / \mathrm{min}) \dagger$ & $48.3 \pm 1.96$ & $35.3 \pm 1.70$ & 0.0002 \\
Total body fat mass $(\mathrm{kg})$ & $12.8 \pm 0.8$ & $20.3 \pm 2.2$ & 0.004 \\
Percent body fat & $17.1 \pm 0.8$ & $23.2 \pm 1.4$ & 0.002 \\
$\mathrm{LTM}(\mathrm{kg})$ & $58.5 \pm 1.2$ & $61.6 \pm 2.0$ & 0.47 \\
$\mathrm{LTM} / \mathrm{height}\left(\mathrm{kg} / \mathrm{m}^{2}\right)$ & $18.5 \pm 0.4$ & $20.0 \pm 0.5$ & 0.03 \\
Bone mineral density $\left(\mathrm{g} / \mathrm{cm}^{2}\right)$ & & & \\
Whole body & $1.113 \pm 0.018$ & $1.186 \pm 0.025$ & 0.08 \\
Femoral neck & $0.786 \pm 0.027$ & $0.799 \pm 0.031$ & 0.88 \\
Lumbar spine & $1.038 \pm 0.039$ & $1.104 \pm 0.043$ & 0.25 \\
Whole body/weight & $0.015 \pm 0.0003$ & $0.014 \pm 0.001$ & 0.15 \\
Femoral neck/weight & $0.011 \pm 0.0004$ & $0.010 \pm 0.0005$ & 0.08 \\
Lumbar spine/weight & $0.015 \pm 0.001$ & $0.014 \pm 0.001$ & 0.31 \\
\hline
\end{tabular}

† Runners, $n=13$; Minimal exercisers, $n=12 .{ }^{*}$ Mann-Whitney U-test.

$P=0.94)$. IGF-I : IGFBP-3 also failed to correlate with adiposity $(r=0.28, P=0.13)$, LTM $(r=0.30, P=$ 0.10 ), or BMD at any site (whole body $r=0.05$, $P=0.77$; femoral neck $r=0.25, P=0.70$; lumbar spine $r=0.03, P=0.86) . \mathrm{VO}_{2}$ max. was not significantly correlated with either IGF-I $(r=0.10, P=0.73)$ or IGF-I : IGFBP-3 $(r=0.23, P=0.27)$, but was positively correlated with total testosterone $(r=0.70$, $P=0.0001)$, SHBG $(r=0.40, P=0.03)$ and FAI $(r=$ $0.40, P=0.04)$. An anticipated inverse relationship was also found between $\mathrm{VO}_{2}$ max. and percent body fat $(r=0.70, P=0.0001)$. Free testosterone, total testosterone, SHBG, FAI, $\mathrm{E}_{1}$ and $\mathrm{E}_{2}$ failed to correlate with adipose mass, LTM, whole body or regional BMD, or muscle strength, but $\mathrm{E}_{1}$ was significantly related to percent body fat $(r=0.40 P=0.03)$. To investigate factors responsible for the marked increase in SHBG in the runners, stepwise multiple regression was performed with $\mathrm{VO}_{2}$ max., age and weight entered as independent variables. Results indicated that only $\mathrm{VO}_{2}$ max. contributed to the observed variance in SHBG $\left(\mathrm{Y}=-27.4+3.62\left(\mathrm{VO}_{2} \max .\right), \mathrm{R}^{2}=0.17\right)$.

\section{Discussion}

We set out to examine putative effects of regular aerobic exercise on the GH/IGF-I and gonadal axes of older men, and to investigate whether such effects might correlate with changes in body composition, bone mineral density or muscle strength. Two novel results emerged

Table 2 Hormonal characteristics. Values are mean \pm S.E.M.

\begin{tabular}{|c|c|c|c|}
\hline & Runners $(n=15)$ & Minimal exercisers $(n=15)$ & ${ }^{\star} \boldsymbol{P}$ value \\
\hline \multicolumn{4}{|l|}{ Somatotropic } \\
\hline IGF-I (ng/ml) & $129 \pm 10$ & $124 \pm 11$ & 0.82 \\
\hline IGFBP-3 (ng/ml) & $2854 \pm 94$ & $2623 \pm 128$ & 0.11 \\
\hline IGF-I:IGFBP-3 & $0.047 \pm 0.04$ & $0.048 \pm 0.04$ & 0.87 \\
\hline \multicolumn{4}{|l|}{ Sex hormones } \\
\hline Free testosterone $(\mathrm{pmol} / \mathrm{l})$ & $47.9 \pm 1.8$ & $47.1 \pm 2.0$ & 0.8 \\
\hline Total testosterone $(\mathrm{nmol} / \mathrm{l})$ & $19.1 \pm 0.8$ & $15.0 \pm 0.9$ & 0.006 \\
\hline SHBG $(\mathrm{nmol} / \mathrm{l})$ & $124.4 \pm 21.6$ & $67.7 \pm 11.6$ & 0.05 \\
\hline $\mathrm{FAl}$ (testosterone/SHBG $\times 100$ ) & $20.7 \pm 2.7$ & $31.4 \pm 4.1$ & 0.04 \\
\hline $\mathrm{E}_{1}(\mathrm{pmol} / \mathrm{l})$ & $85.1 \pm 5.2$ & $108 \pm 6.7$ & 0.03 \\
\hline $\mathrm{E}_{2}(\mathrm{pmol} / \mathrm{l})$ & $73.0 \pm 6.3$ & $81.8 \pm 8.0$ & 0.18 \\
\hline \multicolumn{4}{|l|}{ Bone turnover } \\
\hline Pyridinoline (nmol// per $\mathrm{mmol} / \mathrm{l})$ & $50.3 \pm 8.7$ & $31.7 \pm 4.7$ & 0.15 \\
\hline CICP (ng/ml) & $140.1 \pm 12.9$ & $119.4 \pm 8.8$ & 0.08 \\
\hline Osteocalcin (ng/ml) & $16.5 \pm 1.6$ & $13.7 \pm 1.2$ & 0.07 \\
\hline
\end{tabular}

${ }^{*}$ Mann-Whitney $U$ test. 
Table 3 Muscle strength $(\mathrm{kg})$. Values are mean \pm S.E.M.

\begin{tabular}{lccc}
\hline & Runners $(n=15)$ & Minimal exercisers $(n=15)$ & ${ }^{\star} \boldsymbol{P}$ value \\
\hline Bench press & $48.0 \pm 2.1$ & $43.2 \pm 1.3$ & 0.06 \\
Military press & $38.7 \pm 1.2$ & $38.5 \pm 1.0$ & 0.89 \\
Biceps curl & $24.7 \pm 1.1$ & $24.0 \pm 0.8$ & 0.56 \\
Triceps extension & $22.7 \pm 0.7$ & $23.8 \pm 0.9$ & 0.32 \\
Leg press & $137.0 \pm 7.0$ & $144.1 \pm 3.8$ & 0.38 \\
Leg extension & $60.3 \pm 2.8$ & $51.1 \pm 2.3$ & 0.02 \\
Leg curl & $30.0 \pm 1.7$ & $27.3 \pm 2.0$ & 0.31 \\
Back extension & $80.5 \pm 3.7$ & $81.2 \pm 2.3$ & 0.86 \\
Grip strength & & $45.2 \pm 1.7$ & 0.93 \\
Dominant & $45.4 \pm 1.4$ & $42.5 \pm 1.5$ & 0.76 \\
\hline Non-dominant & $43.1 \pm 1.5$ & & \\
\hline
\end{tabular}

${ }^{*}$ Mann-Whitney $U$ test.

from this analysis. First, consistent with our previous study of resistance-trained older people, it appears that habitual endurance exercise does not ameliorate the age-related decline in circulating IGF-I or its most abundant binding protein, in one estimate of IGF-I bioavailability, the calculated ratio of IGF to IGFBP-3, or, by inference, the decline in $\mathrm{GH}$ secretion. With regard to the latter inference, although we did not measure GH in this study, previous work from our laboratory and from others clearly shows that healthy older men uniformly show decreased GH secretory capacity, either spontaneously or in response to provocative stimuli such as exercise (1-4), and that even an intense and sustained program of exercise training did not restore these deficits (11). The second major finding of this study was that our group of very active older men showed striking increases in circulating SHBG, sufficient to misrepresent calculated estimates of bioavailable testosterone.

The exercising men recruited into this study were all over the age of 60 years and had been running regularly for at least the previous 10 years. Most started running after the age of 40 years and each has continued to run an average of 25-35 miles/week as reported by physical activity questionnaires and supported by high aerobic capacities. As all individuals in our study were healthy, non-diabetic and gave comparable nutritional histories, for convenience we measured IGF-I concentrations to represent somatotropic hormonal status $(2,30)$. Two runners who had trained to international competition standard since youth also had low IGF-I concentrations, which suggests that even early initiation of endurance training does not prevent the eventual age-associated decline in IGF-I status. Indeed, not a single individual in either group had an IGF-I concentration within the normal youthful range ( $\geq 250 \mathrm{ng} / \mathrm{ml})$ (29).

The comparably low IGF-I concentrations but significantly disparate $\mathrm{VO}_{2}$ max. values between our study groups contradict previous findings $(12,14)$ that suggested that the age-associated decline in IGF-I concentration is indicative of reduced physical activity rather than an effect of aging per se. However, whereas Kelly et al. (14) indirectly derived $\mathrm{VO}_{2}$ max. from submaximal exercise tests, a strategy that is unreliable in the elderly (31), aerobic capacity was directly measured in our study participants. It is unlikely, though possible, that the 26 elderly men in the study by Poehlman et al. (13) differed in genetic background compared with our participants, who were Caucasian, but more likely, as recognized by those authors, that their observed correlation between $\mathrm{VO}_{2}$ max. and IGF-I was not statistically significant. Our result does not preclude that an individual older man who habitually exercised might retain a small, albeit severely attenuated IGF-I response, as Poehlman et al. have recently suggested (13), although the increases in IGF-I concentrations observed in that study (which did not include a control group) were small, with a maximum absolute value of $101 \mathrm{ng} / \mathrm{ml}$, remaining well within the range of low values typical for aging men, and would be unlikely to represent a physiologically meaningful increase.

As expected, we observed an inverse relationship between $\mathrm{VO}_{2}$ max. and adiposity, but we found no significant relationship between IGF-I concentrations and percent fat mass in older men. In contrast, in a study of young adults, Weltman et al. (32) demonstrated an inverse relationship between fat mass and IGF-I concentration. Others that examined the same parameters in young and older men did not report subgroup analyses in the same age range as our participants $(1,33)$. The absence of a correlation between IGF-I and percent body fat in older men that we have demonstrated is consistent with the age-related, exerciseindependent suppression of GH/IGF-I that we observed: that is, age per se appears to exert a more potent effect on GH/IGF-I secretion than does adiposity.

Our results also showed no correlation between IGF-I concentrations and muscle strength. We found that muscle strength was comparable between the two groups of men except for leg extension, for which the runners were stronger. Although the runners were endurance rather than strength trained, the fact that they were stronger than the MEM in only one activity-related muscle group suggests that a direct 
training effect rather than the hormonal milieu was responsible for this difference. This result is consistent with those of our previous studies indicating that older men retain the ability to increase muscle strength by resistance training (23), an effect that is not augmented by treatment with recombinant human $\mathrm{GH}$ and induction of IGF-I $(23,34)$. Collectively, these results suggest that deficits in GH/IGF-I secretion do not underlie age-related declines in muscle strength.

The values of whole body, femoral neck and lumbar spine BMD were also similar in both groups. Our MEM weighed more than the runners, but normalizing BMD for weight did not materially alter this result. In contrast to Pocock et al. (35), we found no significant relationship between physical fitness, defined by $\mathrm{VO}_{2}$ max., and bone density. We have previously shown that highimpact weight-bearing activity, such as gymnastics, may provide loading forces powerful enough to stimulate osteogenesis (36). Although running is clearly a weight-bearing activity, peak loads experienced by the axial skeleton may not be sufficient to promote significant gains in bone mass. Our results, therefore, suggest that many years of endurance exercise do not prevent (or accelerate) age-related declines in BMD.

To our surprise, assessment of sex hormone status in runners revealed diminished FAI values attributable to strikingly increased SHBG concentrations, whereas direct RIA of 'free' testosterone concentrations showed comparable values between the groups, suggesting that the runners were not, in fact, hypogonadal. These discrepant results are not easily reconciled. The FAI is purely a mathematical construct, a ratio between concentrations of total testosterone and SHBG. Use of this ratio assumes linearity of hormone binding, even at substantially increased SHBG concentrations, and also assumes that steroid binding constants are not altered by age. The RIA for free testosterone, in contrast, is based on the use of a ligand, in this case a testosterone analog, which binds with strong affinity to polyclonal testosterone antisera but not to SHBG. The performance of this assay in comparison with other clinically used RIAs for 'free' testosterone is excellent. Therefore, while emphasizing that further work is warranted to resolve the nature of bound and free androgens in older men, we consider it most likely that the runners of the current study had normal gonadal function for age.

Circulating SHBG is known to increase with age, and the values we observed for MEM typified those reported for older men (37). The values observed in our runners, averaging $124 \mathrm{nmol} / \mathrm{l}$, far exceeded those associated with known factors (including age) that stimulate SHBG production. The best characterized stimulus for hepatic SHBG synthesis is estrogen, but this was not responsible for the group differences in SHBG concentrations reported here; concentrations of $\mathrm{E}_{2}$, the most potent estrogen, were the same in both groups, whereas $\mathrm{E}_{1}$, the aromatization of which from androstenedione is enhanced by adiposity, was appropriately higher in MEM. Some evidence indicates a role for aerobic physical activity in SHBG production, at least in men. SHBG concentrations have been observed to increase acutely with such exercises as cycle ergometry, and with longer-term endurance training (38-41), although some reports involving endurance-trained younger men have not confirmed this effect $(18,21,37,42)$. As SHBG concentrations vary inversely with circulating insulin (43), a plausible explanation for greater SHBG values in trained older men could be attenuation of agerelated insulin-resistance. Such a mechanism might also explain the failure to observe an SHBG training response in younger men, in whom the overall prevalence of insulin resistance would predictably be lower.

Despite strong evidence for the health benefits of continued aerobic exercise into later life, our results argue that preservation of the somatotropic axis does not result from such activity and therefore does not contribute to this beneficial effect. Furthermore, as SHBG has been claimed to be a reasonably powerful index of cardiovascular risk and has been directly correlated with obesity and insulin resistance (44), our results indicate that interpretation of SHBG concentrations in older men should take into account individual patterns of physical activity.

\section{Acknowledgements}

The authors wish to thank Dr Paul Walton (Diagnostic Systems Laboratories) and Ms Karen Shepard (Metra Biosystems, Inc.) for their generous gifts of reagents necessary to conduct this study. This work was supported by the Research Service, Department of Veterans Affairs.

\section{References}

1 Rudman D, Kutner MH, Rogers CM, Lubin MF, Fleming GA \& Bain RP. Impaired growth hormone secretion in the adult population. Relation to age and adiposity. Journal of Clinical Investigation 198167 1361-1369.

2 Florini JR, Prinz PN, Vitiello MV \& Hintz RL. Somatomedin-C levels in healthy young and old men: relationship to peak and 24hour integrated levels of growth hormone. Journal of Gerontology $1985402-7$.

3 Pyka G, Wiswell R \& Marcus R. Age-dependent effect of resistance exercise on growth hormone secretion in people. Journal of Clinical Endocrinology and Metabolism 199275 404-407.

4 Corpas E, Blackman MR, Roberson R, Scholfield D \& Harman SM. Oral arginine-lysine does not increase growth hormone or insulin-like growth factor-I in old men. Journal of Gerontology 199348 M128-133.

5 Salomon F, Cuneo RC, Hesp R \& Sonksen PH. The effects of treatment with recombinant human growth hormone on body composition and metabolism in adults with growth hormone deficiency. New England Journal of Medicine 1989321 1797-1803.

6 Cuneo RC, Salomon F, Wiles CM, Hesp R \& Sonksen PH. Growth hormone treatment in growth hormone-deficient adults. 1. Effects on muscle mass and strength. Journal of Applied Physiology $199170688-694$.

7 Cuneo RC, Salomon F, Wiles CM, Hesp R \& Sonksen PH. Growth hormone treatment in growth hormone deficiency: 2. Effect on 
exercise performance. Journal of Applied Physiology $199170695-$ 700 .

8 Jorgensen JOL, Pedersen SA, Theusen L, Jorgensen J, IngemannHansen T, Skakkebaek NE \& Christiansen JS. Beneficial effects of growth hormone treatment in GH-deficient adults. Lancet 19891 1221-1225.

9 Rudman D. Growth hormone, body composition and aging. Journal of American Geriatric Society 198533 800-807.

10 Weltman A, Weltman JY, Schurrer R, Evans WS, Veldhuis JD \& Rogol AD. Endurance training amplifies the pulsatile release of growth hormone: effects of training intensity. Journal of Applied Physiology 199272 2188-2196.

11 Pyka G, Taaffe DR \& Marcus R. Effect of a sustained program of resistance training on the acute growth hormone response to resistance exercise in older adults. Hormone and Metabolic Research 199426 330-333.

12 Poehlman ET \& Copeland KC. Influence of physical activity on insulin-like growth factor-I in healthy younger and older men. Journal of Clinical Endocrinology and Metabolism 199071 14681473.

13 Poehlman E, Rosen C \& Copeland K. The influence of endurance training on insulin-like growth factor-I in older individuals. Metabolism 199443 1401-1405.

14 Kelly PJ, Eisman JA, Stuart MC, Pocock NA, Sambrook PN \& Gwinn TH. Somatomedin-C, physical fitness, and bone density. Journal of Clinical Endocrinology and Metabolism 199070 718-723.

15 Longcope C, Goldfield S, Brambilla D \& McKinlay J. Androgens, estrogens, and sex hormone-binding globulin in middle-aged men. Journal of Clinical Endocrinology and Metabolism 199071 $1442-1446$

16 Mitchell R, Hollis S, Rothwell C \& Robertson W. Age related changes in the pituitary-testicular axis in normal men; lower serum testosterone results from decreased bioactive $\mathrm{LH}$ drive. Clinical Endocrinology 199542 501-507.

17 Roberts AC, McClure RD, Weiner RI \& Brooks GA. Overtraining affects male reproductive status. Fertility and Sterility 199360 686-692.

18 Wheeler G, Singh M, Pierce W, Epling W \& Cumming D. Endurance training decreases serum testosterone levels in men without change in luteinizing hormone pulsatile release. Journal of Clinical Endocrinology and Metabolism $199172422-425$.

19 De Souza M, Arce J \& Pescatello L. Gonadal hormones and semen quality in male runners. International Journal of Sports Medicine $199415383-391$.

20 Hackney A, Sinning W \& Bruot B. Reproductive hormonal profiles of endurance-trained and untrained males. Medicine and Science in Sports and Exercise 198820 60-65.

21 Bagatell C \& Bremner W. Sperm counts and reproductive hormones in male marathoners and lean controls. Fertility and Sterility 199053 688-692.

22 MacConnie S, Barkan A, Lampman R, Schork M \& Beitins I. Decreased hypothalamic gonadatropin-releasing hormone secretion in male marathon runners. New England Journal of Medicine $1986315411-417$.

23 Taaffe DR, Pruitt L, Reim J, Hintz RL, Butterfield G, Hoffmann AR \& Marcus R. Effect of recombinant human growth hormone on the muscle strength response to resistance exercise in elderly men. Journal of Clinical Endocrinology and Metabolism 199479 1361-1366.

24 Nanjee M \& Wheeler M. Plasma free testosterone - is an index sufficient? Annals of Clinical Biochemistry 198522 387-390.

25 Holloway L, Butterfield G, Hintz R, Gesundheit N \& Marcus R. Effects of recombinant human growth hormone on metabolic indices, body composition, and bone turnover in healthy elderly women. Journal of Clinical Endocrinology and Metabolism 199479 470-479.

26 Hanson P. Clinical exercise testing. In Resource Manual for Guidelines for Exercise Testing and Prescription, pp 205-222. Eds SN Blair, P Painter, RR Pate, LK Smith \& CB Taylor, American College of Sports Medicine. Philadelphia: Lea \& Febiger, 1988.
27 Borg G. Psychophysical bases of perceived exertion. Medicine and Science in Sports and Exercise 198214 377-381.

28 Snow-Harter C, Bouxsein M, Lewis B, Charette S, Weinstein P \& Marcus R. Muscle strength as a predictor of bone mineral density in young women. Journal of Bone and Mineral Research 19905 589-595.

29 Hintz R, Liu F \& Seegan C. Characterization of an insulin-like growth factor-I/somatomedin-C radioimmunoassay specific for the C-peptide region. Journal of Clinical Endocrinology and Metabolism 198255 927-930.

30 Rudman D, Feller AG, Nagraj HS, Gergans GA, Lalitha PY, Goldberg AF, Schlenker RA, Cohn L, Rudman IW \& Mattson DE. Effects of human growth hormone in men over 60 years old. New England Journal of Medicine 1990323 1-6.

31 Bevier W, Wiswell R, Pyka G, Kozak K, Newhall K \& Marcus R. Relationship of body composition, muscle strength, and aerobic capacity to bone mineral density in older men and women. Journal of Bone and Mineral Research 19894 421-432.

32 Weltman A, Weltman JY, Hartman M, Abbott RD, Rogol AD, Evans WS \& Veldhuis JD. Relationship between age, percentage body fat, fitness, and 24-hour growth hormone release in healthy young adults: effects of gender. Journal of Endocrinology and Metabolism 199478 543-548.

33 Copeland K, Colletti R, Devlin J \& McAuliffe T. The relationship between insulin-like growth factor-I, adiposity and aging. Metabolism 199039 584-587.

34 Taaffe DR, Jin I, Vu T, Hoffman A \& Marcus R. Lack of effect of recombinant human growth hormone on muscle morphology and growth hormone-insulin-like growth factor expression in resistance trained elderly men. Journal of Clinical Endocrinology and Metabolism $199681421-425$.

35 Pocock N, Eisman J, Yeates M \& Sambrook P. Physical fitness is a major determinant of femoral neck and lumbar spine bone mineral density. Journal of Clinical Investigation 198678 618-621.

36 Robinson T, Snow-Harter C, Taaffe DR, Gillis D, Shaw J \& Marcus R. Gymnasts exhibit higher bone mass than runners despite similar prevalence of amenorrhoea and oligomenorrhoea. Journal of Bone and Mineral Research 199510 26-35.

37 Semmens J, Rouse I, Beilin L \& Masarei J. Relationships between age, body weight, physical fitness and sex-hormone-binding globulin capacity. Clinica Chimica Acta 1983133 295-300.

38 Zmuda JM, Thompson PD \& Winters SJ. Exercise increases serum testosterone and sex hormone binding globulin levels in older men. Metabolism 199645 935-939.

39 Caballero MJ, Mena P \& Maynar M. Changes in sex hormone binding globulin, high density lipoprotein cholesterol and plasma lipids in male cyclists during training and competition. European Journal of Applied Physiology and Occupational Physiology 199264 9-13.

40 Gray AB, Telford RD \& Weidemann MJ. Endocrine response to intense interval exercise. European Journal of Applied Physiology $\mathcal{E}$ Occupational Physiology 199366 366-371.

41 Bosco C, Tihanyl J, Rivalta L, Parlato G, Tranquilli C, Pulvirenti G, Foti C, Viru M \& Viru A. Hormonal responses in strenuous jumping effort. Japanese Journal of Physiology 199646 93-98.

42 Gafny M, Silbergeld A, Klinger B, Wasserman M \& Laron Z. Comparative effects of GH, IGF-I and insulin on serum sex hormone binding globulin. Clinical Endocrinology 199441 169-175.

43 Houmard JA, McCulley C, Shinebarger MH \& Bruno NJ. Effects of exercise training on plasma androgens in men. Hormone and Metabolic Research 199426 297-300.

44 Pugeat M, Moulin P, Cousin P, Fimbel S, Nicolas MH, Crave JC \& Lejeune $\mathrm{H}$. Interrelations between sex hormone-binding globulin (SHBG), plasma lipoproteins and cardiovascular risk. Journal of Steroid Biochemistry and Molecular Biology 199553 567-572.

Received 21 October 1997

Accepted 26 January 1998 